

\title{
mRNA expression of prolactin receptor in sheep pituitary and its effect on maternal behavior
}

\author{
L.P. Wang \\ College of Life Science and Technology, Yancheng Teachers University, \\ Yancheng, Jiangsu, China \\ Corresponding author: L.P. Wang \\ E-mail: lpwang76@163.com
}

Genet. Mol. Res. 14 (3): 8650-8657 (2015)

Received October 3, 2014

Accepted April 24, 2015

Published July 31, 2015

DOI http://dx.doi.org/10.4238/2015.July.31.13

\begin{abstract}
Prolactin receptor (PRLR) is the specific receptor for prolactin. Brain-specific control of PRLR gene expression is correlated with the induction of maternal behavior. The aim of this study was to investigate the dynamic changes in the PRLR mRNA level in the sheep pituitary gland and its effect on ewe maternal behavior. The mRNA expression of $P R L R$ during non-pregnancy stage was maintained at low but detectable levels, as was the case during mid-gestation. After that, expression began increasing and reached a maximum during the early postpartum followed by a gradual decline during the mid-postpartum and late postpartum stages. A trend of higher PRLR mRNA expression was observed during the postpartum stage relative to the non-pregnancy and pregnancy stages. Expression of PRLR mRNA was significantly higher in the normal maternal behavior group than that in the abnormal maternal behavior group. There may be a correlation between PRLR mRNA expression and ewe maternal behavior, especially in early postpartum.
\end{abstract}

Key words: Maternal behavior; mRNA expression; Prolactin receptor gene; Sheep 


\section{INTRODUCTION}

The fundamental precondition to the survival and development of lambs is the formation of a close and exclusive bond between the ewe and her lambs. Maternal behavior plays an important role in establishing this bond. Maternal behavior is most commonly used to describe the suite of behaviors expressed by mothers during late gestation and directed towards the offspring throughout lactation until the young are weaned. This behavior is influenced by several factors, including the genotype of the animal, ewe age and experience, breed differences, ewe emotivity, the behavior of the lamb, and management (Dwyer and Lawrence, 1998; Meurisse et al., 2005; Dwyer, 2008a; Plush et al., 2011; von Borstel et al., 2011).

Currently, much of the understanding of the physiological processes and neuroendocrine basis of the onset of maternal behavior is from studies of sheep (Dwyer et al., 1999; Dwyer, 2008b). Although a better understanding of the neuroendocrine processes underlying individual differences in maternal behavior may help to improve maternal behavior by selecting and developing selection strategies, few studies have examined the underlying genetic mechanisms and the genetic basis of maternal behaviors. Animal studies have suggested that genetic variation or the expression level of genes is associated with maternal behavior, including the prolactin receptor, dopamine D4 receptor, oxytocin receptor, arginine vasopressin receptor 1A, and dopamine receptors D1 and D2 (Tanaka, 2002; Tomás et al., 2006; Bakermans-Kranenburg and van Ijzendoorn, 2006; Nishimori et al., 2008; Avinun et al., 2012; Mileva-Seitz et al., 2012).

$\mathrm{Hu}$ sheep is one of the most distinctive local sheep breeds in China. As a result of a long process of acclimatization and artificial selection, $\mathrm{Hu}$ sheep are widely recognized for their beautiful wavy lambskins, early sexual maturity, seasonal breeding, fast growth, prolificacy, and adaptability to a hot and humid climate. Hu sheep is a world-famous breed because of its high prolificacy. The average litter size of ewes raised under extensive conditions is 2.29 (Wang et al., 2000). The aim of this study was to determine the expression profile of prolactin receptor (PRLR) mRNA in the Hu sheep pituitary during the ewe's pregnancy and labor cycle. In addition, we examined the effects of PRLR mRNA expression on maternal behavior to elucidate the physiological role of PRLR during early postpartum.

\section{MATERIAL AND METHODS}

\section{Animals and tissue collection}

All experimental animals were obtained from the Hu Sheep Resources Conservation Zone of Jiangsu Province in China. Healthy pregnant ewes of uniform age (3 years) were selected from an experimental shed and used in the present study. The ewes were maintained under well-ventilated and proper hygienic conditions. Test ewes were slaughtered at each stage and the pituitary tissues were rapidly dissected from the brain. The collected pituitary tissues were snap-frozen in liquid nitrogen and stored at $-80^{\circ} \mathrm{C}$. Animal care and use was approved by the Animal Care and Use Committee of Yancheng Teachers University. 


\section{RNA isolation and cDNA synthesis}

Total RNA was isolated from approximately $50 \mathrm{mg}$ frozen pituitary tissues with the use of RNAprep pure Tissue Kit (Tiangen Biotech, Beijing, China) according to manufacturer instructions. RNA quality, quantity, and integrity were verified by agarose gel electrophoresis and a NanoDrop spectrophotometer (ND-2000, Wilmington, DE, USA). Two micrograms of total RNA was then reverse-transcribed into cDNA using random primers with a high-capacity reverse transcriptase kit (Applied Biosystems, Foster City, CA, USA). The reverse transcription cycle program was as follows: $25^{\circ} \mathrm{C}$ for $10 \mathrm{~min}, 37^{\circ} \mathrm{C}$ for $120 \mathrm{~min}$, and $85^{\circ} \mathrm{C}$ for $5 \mathrm{~s}$ in a thermal cycler. Glyceraldehyde 3-phosphate dehydrogenase (GAPDH) was used as an internal control to confirm the amplification of each cDNA. cDNA samples were stored at $-20^{\circ} \mathrm{C}$.

\section{Quantitative real-time PCR (qPCR)}

Sheep-specific primers for the target PRLR gene were designed using the Primer Express Program (Applied Biosystems) according to manufacturer guidelines. The succinate dehydrogenase complex, subunit A (SDHA) and GAPDH genes were chosen as reference genes to normalize expression levels of the target gene (Table 1).

Table 1. Primers used for quantitative real-time PCR in sheep pituitary.

\begin{tabular}{llc}
\hline Target gene & Primer sequence (5'-3') & Fragment size (bp) \\
\hline PRLR & F: CTTACCACAACATTGCTGACG & 231 \\
SDHA & R: GTTTAGCAGAGAACAAGGGGG & 185 \\
& F: GCAGAACCTGATGCTTTGTG & \\
GAPDH & R: CGTAGGAGAGCGTGTGCTT & 114 \\
& F: CTGGTGCTGAGTACGTGGTG & \\
\hline
\end{tabular}

SYBR Green real-time PCR amplification was conducted using an iCycler iQ5 RealTime Detection System (Bio-Rad, Hercules, CA, USA). qPCR was carried out in a $25-\mu \mathrm{L}$ reaction mixture, which included $12.5 \mu \mathrm{L}$ SYBR Premix Ex Taq, $0.4 \mu \mathrm{M}$ of each primer, and $1 \mu \mathrm{L}$ cDNA. PCR conditions were as follows: initial incubation at $95^{\circ} \mathrm{C}$ for $3 \mathrm{~min}$ and then 40 cycles at $95^{\circ} \mathrm{C}$ for $5 \mathrm{~s}$ and $60^{\circ} \mathrm{C}$ for $30 \mathrm{~s}$. Each PCR was performed in triplicate for each cDNA sample to ensure reproducibility. To determine the specificity of the PCR, a dissociation curve was generated after amplification was complete. Relative quantification analyses were performed using the comparative CT method, and the relative gene expression was calculated by using the $2^{-\Delta \Delta \mathrm{Ct}}$ method (Livak and Schmittgen, 2001).

\section{Analysis of expression pattern of PRLR mRNA}

To evaluate the mRNA expression of PRLR in the brain, experiments were classified into 6 stages at set times in a ewe's pregnancy and labor cycle. The stages consisted of nonpregnancy, mid gestation (day 70-80 before labor), late gestation (day 5-10 before labor), early postpartum (day 3 after labor), mid postpartum (day 10 after labor), and late postpartum (day 30 after labor). 
To test whether mRNA expression in the pituitary tissue after labor was correlated with maternal behavior, changes in PRLR mRNA expression were analyzed. Behaviors of the ewes were observed continuously for $12 \mathrm{~h}$ after labor. Four maternal behaviors were observed, including groom lamb, accept lamb at the udder and suck, aggressive to lamb, and reject lamb at the udder and suck. The ewes were divided into 2 groups according to their observed maternal behaviors. If a ewe was observed to be aggressive to a lamb, reject lamb at the udder and suck, it was included in the group of abnormal maternal behaviors (AMB group). The other ewes without these 2 observed maternal behaviors were divided into the group of normal maternal behaviors (NMB group). The 2 groups were slaughtered immediately for pituitary tissue collection when the experiments were complete.

\section{Statistical analyses}

All experimental data are reported as means \pm SE. Differences in mRNA expression levels were assessed using the SPSS software (SPSS, Inc., Chicago, IL, USA) with one-way analysis of variance. Differences were considered to be significant when $\mathrm{P}<0.05$.

\section{RESULTS}

The expression of PRLR mRNA was analyzed by qPCR during the pregnancy and labor cycles (Figure 1). For each pituitary tissue sample, PRLR mRNA expression was calculated relative to the mRNA expression of the endogenous controls SDHA and GAPDH. We found that PRLR mRNA expression compared to GAPDH was lower than that relative to SDHA mRNA expression. However, a similar expression pattern of PRLR mRNA was observed during different stages based on SDHA and GAPDH mRNA expression. The mRNA expression of PRLR during the non-pregnancy stage maintained at a low but detectable level, as was the case in mid-gestation, after which expression level began increasing and reached a maximum during early postpartum followed by a gradual decline during the mid-postpartum and late postpartum stages. Although PRLR mRNA was expressed in the pituitary tissues throughout the pregnancy and labor cycles, a significant difference was detected across stages. In addition, higher PRLR mRNA expression was observed during the postpartum stage relative to the non-pregnancy and pregnancy stages.

To determine whether the expression of PRLR mRNA affects maternal behavior, the temporal expression in pituitary tissues at $12 \mathrm{~h}$ after labor was determined in each group. Expression of PRLR mRNA was significantly higher $(\mathrm{P}<0.05)$ in the NMB group than in the AMB group (Figure 2). The 2 reference genes also showed the same information regarding PRLR mRNA expression via qPCR analysis when compared to each other.

\section{DISCUSSION}

Quantification of gene transcription levels plays a central role in the understanding of gene function and alterations in regulation (Overbergh et al., 2003). Therefore, quantitative real-time PCR has become a popular means for assessing mRNA expression level because of its accuracy and sensitivity in the quantification of mRNA signals (Derveaux et al., 2010; Johnson et al., 2014). It is essential to control for error between samples when measuring RNA 
expression. To normalize gene expression, housekeeping genes are used under the assumption that expression is invariable under different experimental conditions, so that they can serve as internal references. Several genes have been used as housekeeping genes ( $\beta$-actin, GAPDH, $\beta 2$-microglobulin, cyclooxygenase 1 , hypoxanthine phosphoribosyl transferase 1 , glucose6-phosphate dehydrogenase, cyclophilin A, tubulin, transferrin receptor, and $18 \mathrm{~S}$ ribosomal RNA), of which the genes encoding $\beta$-actin and GAPDH are most commonly used (Lee et al., 2001; Huggett et al., 2005; Sun et al., 2012). However, the weaknesses of most reference genes have been discussed in the literature and pertain mainly to the stability or variation in their expression under different conditions (Kim et al., 2011; Lin and Redies, 2012; Hellemans and Vandesompele, 2014). Thus, 2 or more genes are recommend as endogenous controls to normalize mRNA expression in different experiments. In this study, SDHA and GAPDH were selected as reference genes to be run simultaneously to normalize PRLR expression levels using real-time qPCR with SYBR green. Our results suggested that all relative expression of PRLR mRNA with regard to GAPDH was higher than that with regard to SDHA mRNA expression. However, one-way analysis of variance showed no significant difference in the mRNA expression between GAPDH and SDHA across all stages. This result was consistent with the expression pattern of GAPDH expression being higher than SDHA expression, and a combination of GAPDH and SDHA was found to be the most suitable when examining expression in the pituitary of dairy and meat cattle breeds (Lisowski et al., 2008). Thus, the expression stability results showed that GAPDH and SDHA genes were suitable for normalizing quantitative real-time PCR data and could be used to determine relative expression levels of PRLR mRNA in the sheep pituitary.

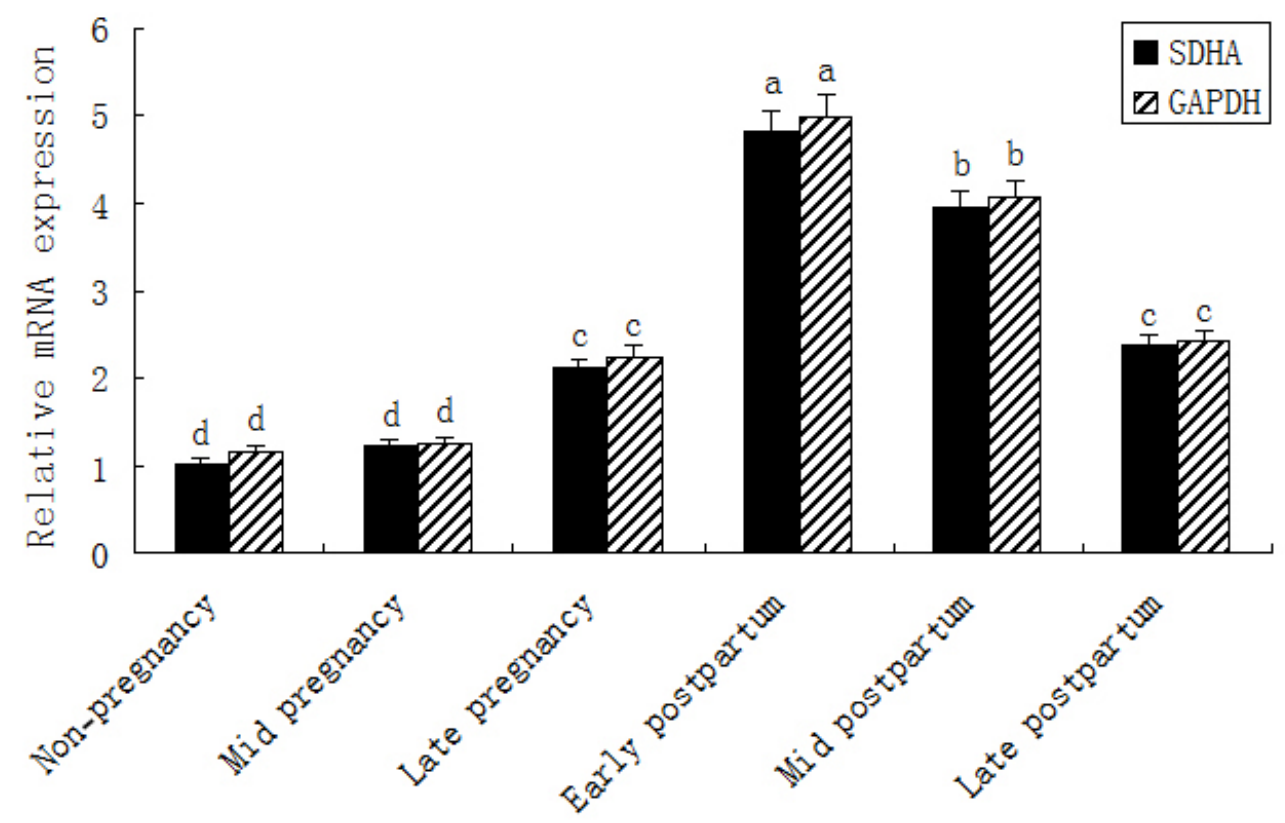

Figure 1. Expression level of PRLR mRNA at different stages in sheep pituitary. Significant differences $(\mathrm{P}<0.05)$ are indicated by different superscript letters and the same superscript letters mean no significant. 


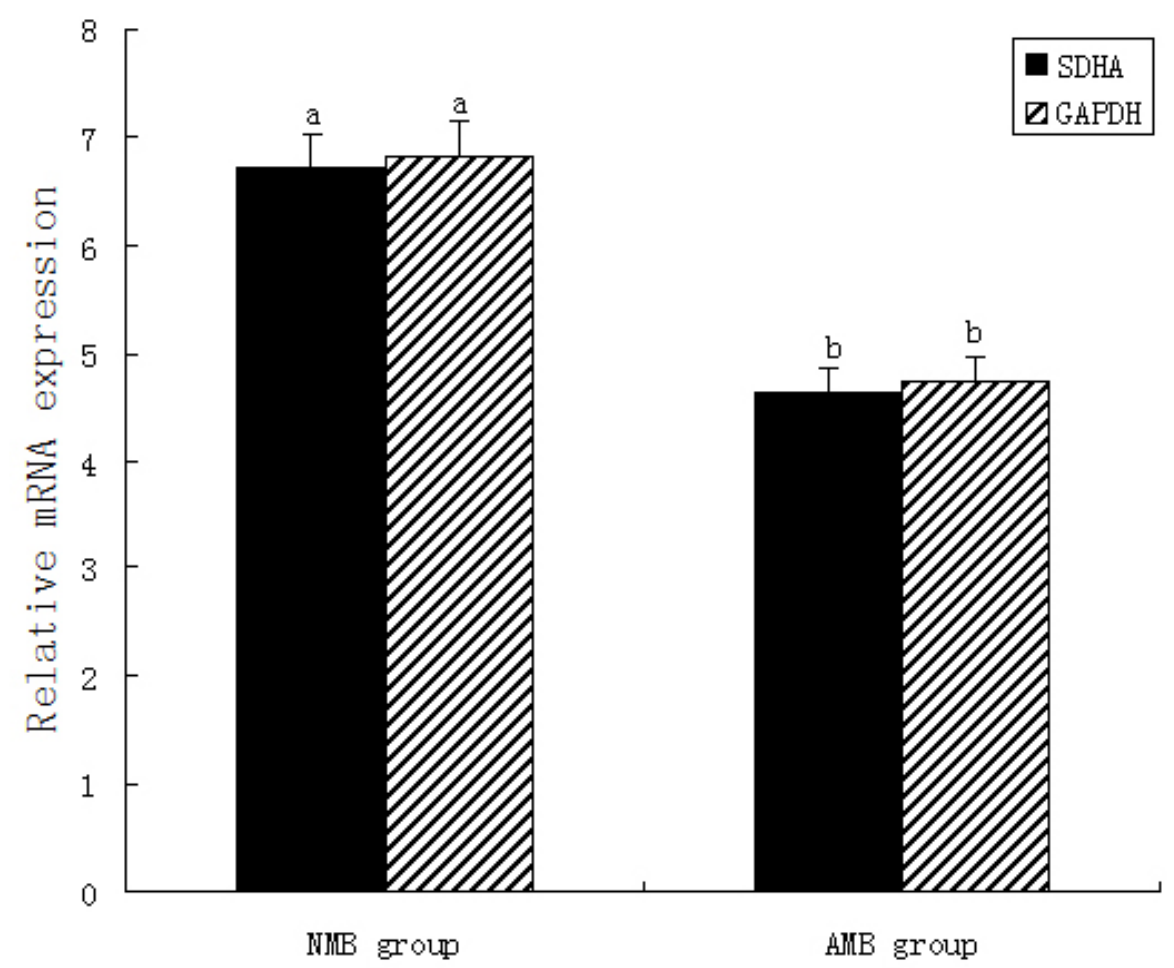

Figure 2. Expression level of PRLR mRNA between the NMB group and the AMB group in the pituitary after ewe labor. Significant differences $(\mathrm{P}<0.05)$ are indicated by different superscript letters and the same superscript letters mean no significant. $\mathrm{NMB}=$ normal maternal behaviors; $\mathrm{AMB}=$ abnormal maternal behaviors.

Prolactin is a polypeptide hormone primarily synthesized in the anterior pituitary. It regulates a variety of functions in mammals, including stress responses, maternal behavior, reproduction, mammary gland development, and lactation (Farmer et al., 1999; Kaminska et al., 2000; Bachelot and Binart, 2007). These actions are mediated by a specific cell surface receptor known as PRLR. Depending on the species considered, PRLR is expressed as a short and/or long form (Bignon et al., 1997; Trott et al., 2003). The 2 forms of PRLR differ only in length and sequence of their cytoplasmic domains. They appear to arise from alternative splicing of the same primary RNA transcript. Significant attention has focused on the potential use of the PRLR gene as a marker for reproductive performance in several mammalian species. Recently, it was reported that PRLR plays an essential role in the induction of the maternal behavior (Lucas et al., 1998; Kelly et al., 2001; Baran et al., 2002; Tomás et al., 2006; Cui et al., 2007; Chen et al., 2010). These results clearly establish PRLR as a regulator of maternal behavior. However, whether an association exists between PRLR and maternal behavior in sheep remains unknown. When PRLR mRNA was quantified in the maternal rat brain during pregnancy and lactation, it was found that PRLR expression was increased in lactating rats compared with in non-pregnant animals (Augustine et al., 2003). The high levels of expression of PRLR in specific brain regions may play a role in transporting prolactin from the peripheral 
circulation into the central nervous system and support a role for prolactin in regulating neuroendocrine and behavioral adaptations in the maternal brain. In previous studies, PRLR knockout mice showed a deficiency in pup contact-induced maternal behavior, indicating that PRLR plays an essential role in the induction of the maternal behavior (Ormandy et al., 1997; Lucas et al., 1998; Tanaka, 2002). These studies clearly establish PRLR as a regulator of maternal behavior. In this study, real-time PCR was conducted to investigate PRLR mRNA expression in the sheep pituitary during the ewe's pregnancy and labor cycle. The results indicated that the mRNA level of PRLR was changed in all stages and that the highest level was observed in the early postpartum stage compared to in other stages. Additionally, the mRNA expression levels of PRLR in the pituitary after ewe labor were significantly different between the NMB group and the AMB group in the early postpartum stage. A correlation may exist between PRLR mRNA expression and ewe maternal behavior, particularly during the early postpartum stage.

\section{ACKNOWLEDGMENTS}

Research supported by the National Natural Science Foundation of China (\#31101747), the Natural Science Foundation of Jiangsu Province (\#BK20141259), the Six Talent Peaks Project in Jiangsu Province, and Sponsored by the Qing Lan Project of Jiangsu Province

\section{REFERENCES}

Augustine RA, Kokay IC, Andrews ZB, Ladyman SR, et al. (2003). Quantitation of prolactin receptor mRNA in the maternal rat brain during pregnancy and lactation. J. Mol. Endocrinol. 31: 221-232.

Avinun R, Ebstein RP and Knafo A (2012). Human maternal behaviour is associated with arginine vasopressin receptor 1A gene. Biol. Lett. 8: 894-896.

Bachelot A and Binart N (2007). Reproductive role of prolactin. Reproduction 133: 361-369.

Bakermans-Kranenburg MJ and van Ijzendoorn MH (2006). Gene-environment interaction of the dopamine D4 receptor (DRD4) and observed maternal insensitivity predicting externalizing behavior in preschoolers. Dev. Psychobiol. 48: 406-409.

Baran N, Kelly PA and Binart N (2002). Characterization of a prolactin-regulated gene in reproductive tissues using the prolactin receptor knockout mouse model. Biol. Reprod. 66: 1210-1218.

Bignon C, Binart N, Ormandy C, Schuler LA, et al. (1997). Long and short forms of the ovine prolactin receptor: cDNA cloning and genomic analysis reveal that the two forms arise by different alternative splicing mechanisms in ruminant and in rodents. J. Mol. Endocrinol. 19: 109-120.

Chen CY, Zhu WC, Li PH, Wei N, et al. (2010). Associations of porcine prolactin (PRL) and prolactin receptor (PRLR) with sow maternal infanticide behavior and litter size in a White Duroc x Erhualian F2 resource population. Sci. Agric. Sin. China 43: 2347-2354.

Cui SQ, Li JH, Cui WG and Bao J (2007). Preliminary study on the relationship between sow maternal behaviour during early lactation and polymorphism of PRLR gene. Yi Chuan 29: 47-51.

Derveaux S, Vandesompele J and Hellemans J (2010). How to do successful gene expression analysis using real-time PCR. Methods 50: 227-230.

Dwyer CM (2008a). Genetic and physiological determinants of maternal behavior and lamb survival: implications for low-input sheep management. J. Anim. Sci. 86: E246-E258.

Dwyer CM (2008b). Individual variation in the expression of maternal behaviour: a review of the neuroendocrine mechanisms in the sheep. J. Neuroendocrinol. 20: 526-534.

Dwyer CM and Lawrence AB (1998). Variability in the expression of maternal behaviour in primiparous sheep: effects of genotype and litter size. Appl. Anim. Behav. Sci. 58: 311-330.

Dwyer CM, Dingwall WS and Lawrence AB (1999). Physiological correlates of maternal-offspring behaviour in sheep: a factor analysis. Physiol. Behav. 67: 443-454.

Farmer C, Sorensen MT, Robert S and Petitclerc D (1999). Administering exogenous porcine prolactin to lactating sows: 
milk yield, mammary gland composition, and endocrine and behavioral responses. J. Anim. Sci. 77: 1851-1859.

Hellemans J and Vandesompele J (2014). Selection of reliable reference genes for RT-qPCR analysis. Methods Mol. Biol. 1160: $19-26$.

Huggett J, Dheda K, Bustin S and Zumla A (2005). Real-time RT-PCR normalisation; strategies and considerations. Genes Immun. 6: 279-284.

Johnson G, Nour AA, Nolan T, Huggett J, et al. (2014). Minimum information necessary for quantitative real-time PCR experiments. Methods Mol. Biol. 1160: 5-17.

Kaminska B, Opalka M, Ciereszko RE and Dusza L (2000). The involvement of prolactin in the regulation of adrenal cortex function in pigs. Domest. Anim. Endocrinol. 19: 147-157.

Kelly PA, Binart N, Lucas B, Bouchard B, et al. (2001). Implications of multiple phenotypes observed in prolactin receptor knockout mice. Front. Neuroendocrinol. 22: 140-145.

Kim I, Yang D, Tang X and Carroll JL (2011). Reference gene validation for qPCR in rat carotid body during postnatal development. BMC Res. Notes 4: 440.

Lee PD, Sladek R, Greenwood CMT and Hudson TJ (2001). Control genes and variability: absence of ubiquitous reference transcripts in diverse mammalian expression studies. Genome Res. 12: 292-297.

Lin JT and Redies C (2012). Histological evidence: housekeeping genes beta-actin and GAPDH are of limited value for normalization of gene expression. Dev. Genes Evol. 222: 369-376.

Lisowski P, Pierzchała M, Gościk J, Pareek CS, et al. (2008). Evaluation of reference genes for studies of gene expression in the bovine liver, kidney, pituitary, and thyroid. J. Appl. Genet. 49: 367-372.

Livak KJ and Schmittgen TD (2001). Analysis of relative gene expression data using real-time quantitative PCR and the 2(-Delta Delta C(T)) method. Methods 25: 402-408.

Lucas BK, Ormandy CJ, Binart N, Bridges RS, et al. (1998). Null mutation of the prolactin receptor gene produces a defect in maternal behavior. Endocrinology 139: 4102-4107.

Meurisse M, Gonzalez A, Delsol G, Caba M, et al. (2005). Estradiol receptor-alpha expression in hypothalamic and limbic regions of ewes is influenced by physiological state and maternal experience. Horm. Behav. 48: 34-43.

Mileva-Seitz V, Fleming AS, Meaney MJ, Mastroianni A, et al. (2012). Dopamine receptors D1 and D2 are related to observed maternal behavior. Genes Brain Behav. 11: 684-694.

Nishimori K, Takayanagi Y, Yoshida M, Kasahara Y, et al. (2008). New aspects of oxytocin receptor function revealed by knockout mice: sociosexual behaviour and control of energy balance. Prog. Brain Res. 170: 79-90.

Ormandy CJ, Camus A, Barra J, Damotte D, et al. (1997). Null mutation of the prolactin receptor gene produces multiple reproductive defects in the mouse. Genes Dev. 11: 167-178.

Overbergh L, Giulietti A, Valckx D, Decallonne B, et al. (2003). The use of real-time reverse transcriptase PCR for the quantification of cytokine gene expression. J. Biomol. Tech. 14: 33-43.

Plush KJ, Hebart ML, Brien FD and Hynd PI (2011). The genetics of temperament in Merino sheep and relationships with lamb survival. Appl. Anim. Behav. Sci. 134: 130-135.

Sun Y, Li Y, Luo D and Liao DJ (2012). Pseudogenes as weaknesses of ACTB (Actb) and GAPDH (Gapdh) used as reference genes in reverse transcription and polymerase chain reactions. PLoS One 7: e41659.

Tanaka M (2002). Brain-specific control of prolactin receptor gene expression correlated with induction of maternal behavior in the rat. J. Reprod. Dev. 48: 103-110.

Tomás A, Casellas J, Ramírez O, Muñoz G, et al. (2006). High amino acid variation in the intracellular domain of the pig prolactin receptor (PRLR) and its relation to ovulation rate and piglet survival traits. J. Anim. Sci. 84: 1991-1998.

Trott JF, Hovey RC, Koduri S and Vonderhaar BK (2003). Alternative splicing to exon11 of human prolactin receptor gene results in multiple isoforms including a secreted prolactin binding protein. J. Mol. Endocrinol. 30: 31-47.

von Borstel UK, Moors E, Schichowski C and Gauly M (2011). Breed differences in maternal behaviour in relation to lamb (Ovis orientalis aries) productivity. Livest. Sci. 137: 42-48.

Wang YX, Yan YQ, Cheng RH, Wang SY, et al. (2004). Effects of single fecundity selection in Hu sheep. Contemp. Anim. Husbandry 4: 31-32. 